\title{
DEGRADATION OF THE STATE OF A BALL TRACK AT THE ZP 6600
}

\author{
Petr KLOUDA ${ }^{1}$, Vlastimil MONI ${ }^{1}$, Jan BLATA ${ }^{2}$ \\ Lubomír DONÁT $T^{3}$, František HELEBRANT ${ }^{2}$ \\ Brown Coal Research Institute j. s. c., Most ${ }^{1}$ \\ VŠB-Technical University of Ostrava ${ }^{2}$ \\ Northern energy a.s. Most ${ }^{3}$
}

\begin{abstract}
:
The article deals with the examination of the state of the ball track of the heavy mining machine ZP6600/Z79. It gives results of material exams which were taken on given samples and describes the progress and results of the numerical computation of the state of tenseness by finite element method of the bottom part of the ball track when it touches the ball.
\end{abstract}

Key words: ball track, sample, material exam, state of tenseness, contact tension

\section{INTRODUCTION}

An original idea came from the SD a.s. - Doly Bílina, the idea of a replacement of a ball track at the heavy machine ZP 5500.5 with a ball track from the heavy machine ZP6600/Z79 [3]. This track was already worn, too. The radius of a groove within the bottom parts of the track and the radius of balls were almost identical. The friction was increasing and pieces of the track material were torn out. The decision about the renovation of the track depended on the determination of the groove size degradation at the ball track. The measuring was made by the employees of the SD a.s. - Doly Bílina in cooperation with workers from VÚHU a. s. Most $[2,4]$. The material tests were undertaken on the given samples of the bottom part of the ball track at the heavy machine and a numeric simulation $[5,6]$ of the tenseness state in the contact area of the ball and the bottom part of the track. The result was an evidence for the decision about the depth of the turned layer of the material in order to create a new groove of the bottom part of the ball track [1].

The material tests were realized in an external cooperation with the company UNIPETROL RPA s.r.o., a testing laboratory number 1050 accredited by ČIA. The numeric simulation of the tenseness was made in the VÚHU a.s. on the 3D model of the contact by a method of the ultimate elements.

The given parameters:

- the bottom part is made from the steel 16540.8,

- the balls are made from the steel GCr15SiMn (G20Mn5; AISI 5210; DIN 100Cr6),

- the total weight of the rotating top of the heavy machine is 1580 tons.

The following Fig. 1 shows the surface state of the groove at the bottom part of the track.

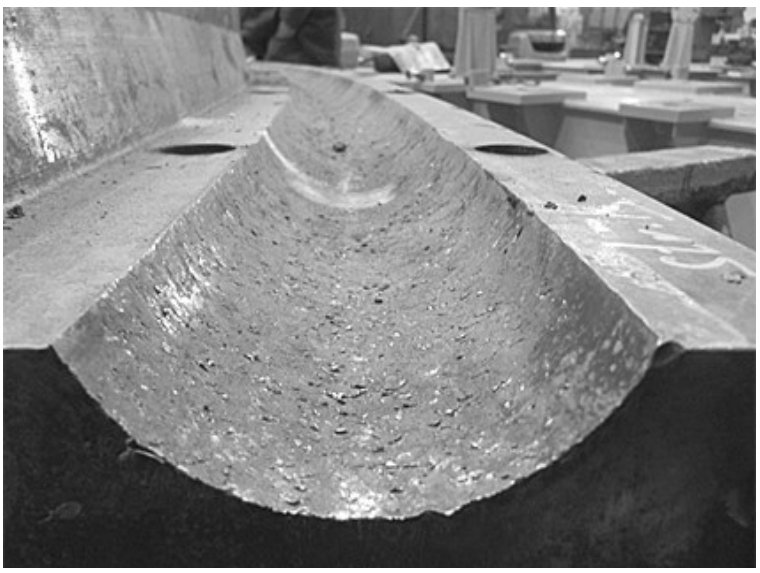

Fig. 1 A groove of the track part

\section{MATERIAL TESTS}

After the consultation with the material laboratory, the collection of samples was made from the maximally loaded bottom part of the ball track (marked as Stv A). Three couples of samples were taken, marked as $2 \mathrm{~s}, 4 \mathrm{~s}$ and $7 \mathrm{~s}$. Each couple consisted of one sample (a shorter one) from the lowest point of the ball track and of one sample from unused area of the bottom part next to the track itself. The collection was made by drilling with a crown drill during a slow travel and proper cooling. The following picture (Fig. 2) shows the collected samples.

The structure of the tests was following:

- chemical structure of the material,

- hardness in the connection with the depth of the track,

- metallographic analysis.

The results of the tests are described in the protocol 399/13. 


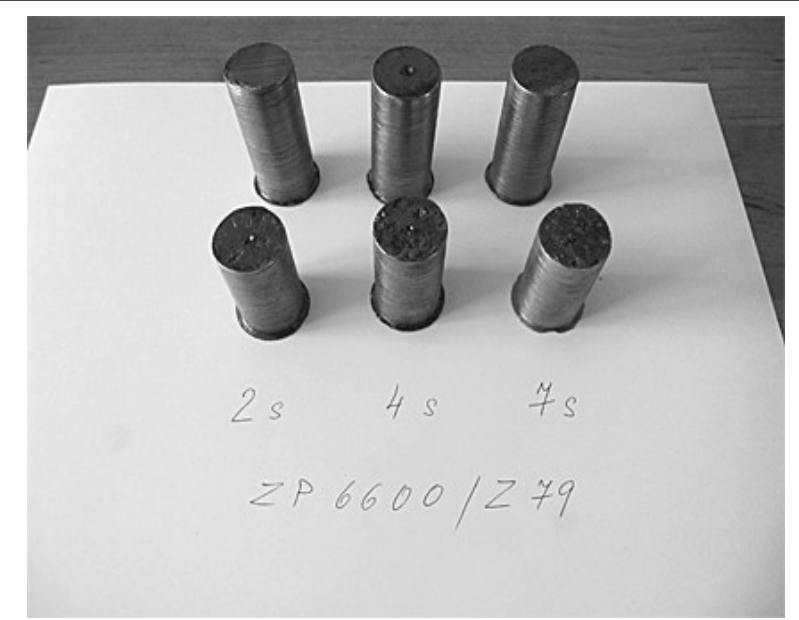

Fig. 2 The collected samples
The chemical analysis - it proves the declared steel 15341. Only the content of the carbon is higher $-0.48 \%$. In accordance with ČSN, the maximal content of the carbon is $0.43 \pm 0.02 \%$. The results are summarized in the following tables (Table 1, 2).

We can match values of the material hardness from the: http://www.taegutec.cz/innotool/ prirucka_obrabeni_341.pdf, with the collected data.

It is obvious that the strength (Table 2), of the material is not influenced so much by the operation of the track.

\section{METALLOGRAPHY}

Detailed results of the made metallographic tests are declared in the laboratory protocol 399/13. There were microscopic cracks and structure deformations found on the samples $A$ from the bottom point of the ball track (contact of the ball with the groove).

Table 1

Hardness of the tested samples

\begin{tabular}{|c|c|c|c|c|}
\hline \multirow{3}{*}{$\begin{array}{c}\text { Depth } \\
\mathrm{mm}\end{array}$} & \multicolumn{3}{|c|}{ Hardness in the ball track HV10 } & \multirow{2}{*}{$\begin{array}{c}\text { Hardness off the ball track HV10 } \\
\text { Sample }\end{array}$} \\
\hline & Sample & Sample & Sample & \\
\hline & $2 s-2 A$ & $4 s-4 A$ & $7 s-7 A$ & $2 s-2 B$ \\
\hline 2 & 280 & 265 & 267 & 270 \\
\hline 4 & & 276 & & \\
\hline 6 & 289 & 269 & 259 & 290 \\
\hline 8 & & 263 & & \\
\hline 10 & 279 & 264 & 260 & 272 \\
\hline 12 & & 246 & & \\
\hline 14 & 299 & 249 & 267 & 277 \\
\hline 16 & & 259 & & \\
\hline 18 & & 248 & & 279 \\
\hline 20 & 286 & 257 & 260 & 274 \\
\hline
\end{tabular}

Table 2

Hardness of the tested samples

\begin{tabular}{ccccc}
\hline \multicolumn{3}{c}{ Strength in the track MPa } & Strength off the track MPa \\
\hline $\begin{array}{c}\text { Depth } \\
\text { mm }\end{array}$ & Sample & Sample & Sample & Sample \\
2 & 900 & $4 s-4 A$ & $85-7 A$ & 865 \\
4 & 850 & 884 & 832 & 930 \\
6 & 927 & 862 & & 871 \\
8 & & 844 & \\
10 & 896 & 847 & 835 & 888 \\
12 & & 788 & & 896 \\
14 & 962 & 797 & & 877 \\
16 & & 832 & 835 & \\
\hline
\end{tabular}


These cracks are maximally $0.6 \mathrm{~mm}$ deep. On the samples $B$ (unused area of the bottom part), there were some structure deformations found. The maximal depth is 0.16 $\mathrm{mm}$.

In accordance with the results, the structure of the groove is influenced by the operation life of the ball track to the maximal depth of $0.6 \mathrm{~mm}$. The material of the track is not so homogenous.

The selected pictures from the protocol are displayed on the following Fig. 3, 4 and 5.
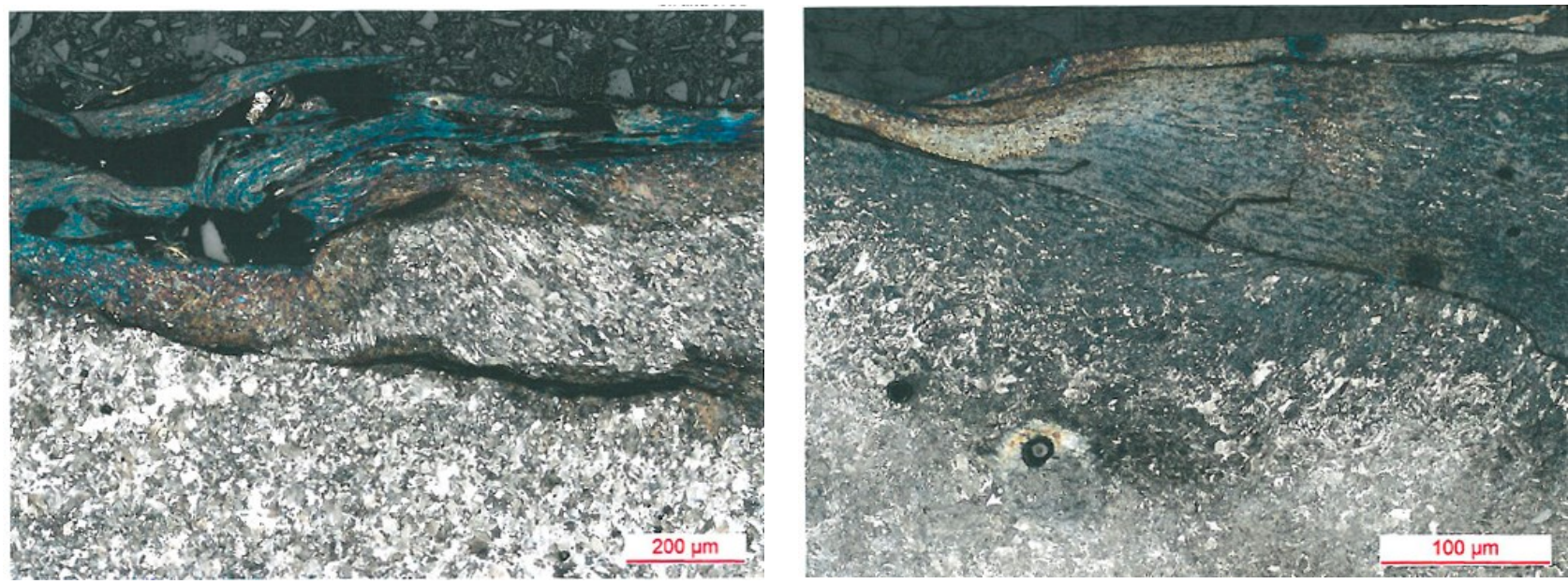

Fig. 3 The depth of cracks in sample $4 A$ of the material collected from the bottom part of the track groove
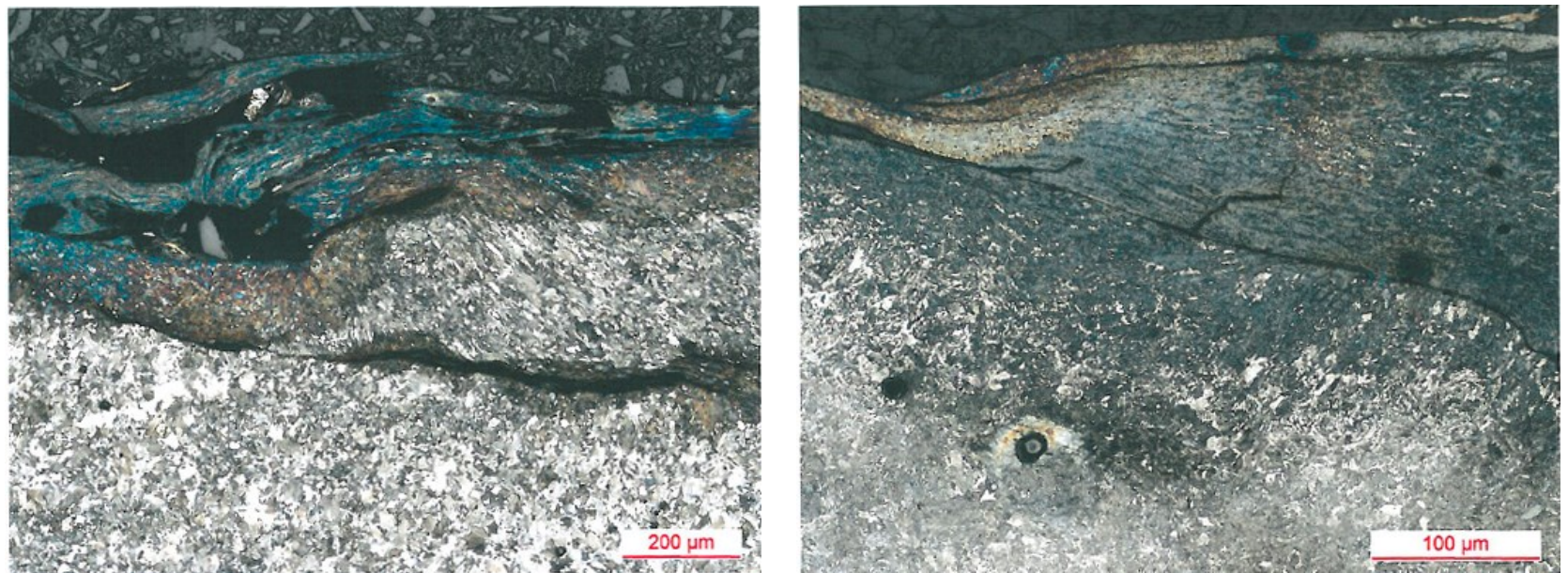

Fig. 4 The depth of cracks in sample 7A of the material collected from the bottom part of the track groove
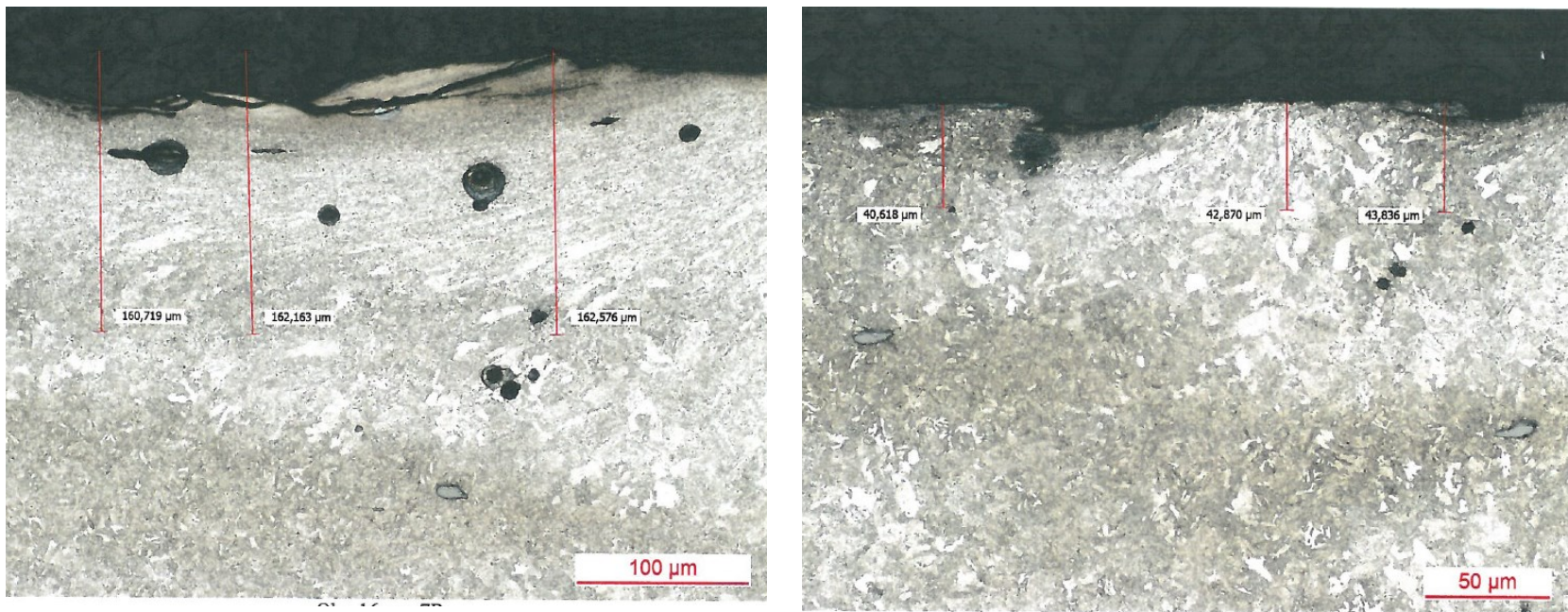

Fig. 5 The deformation of material of the sample $7 B$ collected outside the groove of the track 


\section{THE SIMULATION OF THE TENSENESS STATE IN THE CON- TACT OF THE BALL WITH THE GROOVE}

To determine the internal and contact forces in the ball and the bottom part of the ball track we used the software called COSMOS/DesignStar ver. 6.0 developed by the company Structural Research and Analysis Corporation. This software uses a method of the ultimate elements.

Characteristic values of the material:

Bottom part steel $15341.9 \mathrm{f}_{\mathrm{u}}=\mathrm{R}_{\mathrm{m}}=880-1050 \mathrm{MPa}$

$\mathrm{f}_{\mathrm{y}}=\mathrm{R}_{\mathrm{K}}=\min 475 \mathrm{MPa}$

sum of contraction $v=0.3$

Tensibility $14 \%$ measured weight $7800 \mathrm{~kg} \cdot \mathrm{m}^{-3}$

Ball steel GCr15SiMn $\mathrm{f}_{\mathrm{u}}=\mathrm{R}_{\mathrm{m}}=\min 900 \mathrm{MPa}$

(AISI 5210) $\quad \mathrm{f}_{\mathrm{y}}=\mathrm{R}_{\mathrm{K}}=\min 500 \mathrm{MPa}$

tensibility $5 \%$

measured weight $7500 \mathrm{~kg} \cdot \mathrm{m}^{-3}$

Geometry

The sizes and the shape of the calculated 3D model were taken from the drawing V004693 „Obnova kulové dráhy zakladače ZP6600.10“. A model consisting of a ball and a bottom part of the track was made. The sizes of both subjects were modified in accordance with the distance between the balls. You can see the model on Fig. 6 .

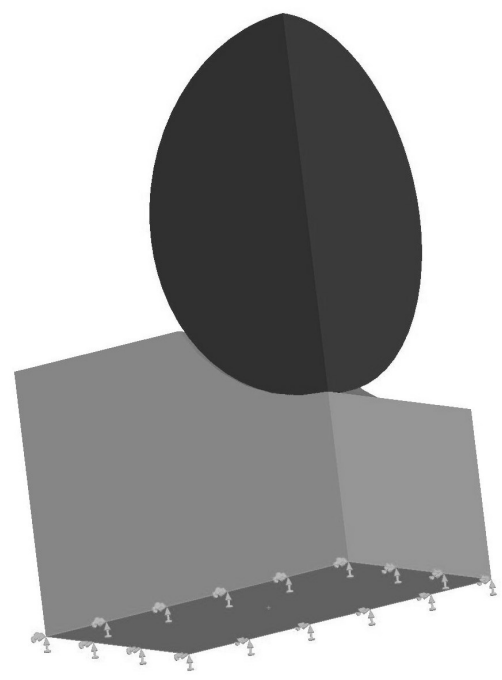

Fig. 6 The model of the contact between the ball and the groove

\section{Supporting - aside conditions}

The bottom part of the track is situated with its lowest area on a fixed support. The vertical areas of the bottom part, which are common with the missing symmetrical part, have so called symmetric placement. It means the placement which simulates internal forces in the common area of the model and the missing part. A similar symmetric placement was applied on the given areas at $1 / 4$ of the ball model. See Fig. 6, 7 and 8.

\section{Data about the model}

There was a net of the ultimate elements of the type TETRA 10 created on the model. Their nominal size was $6.095 \mathrm{~mm}$ with the local adjustment of the net in the contact areas of the ball with the bottom part to the size 0.2 $\mathrm{mm}$ of the element.

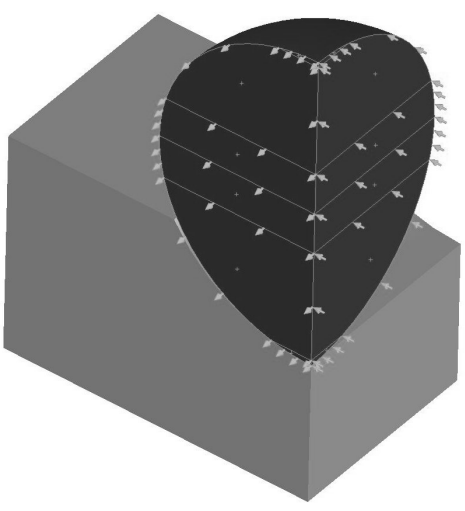

Fig. 7 Symmetrical placement of the ball

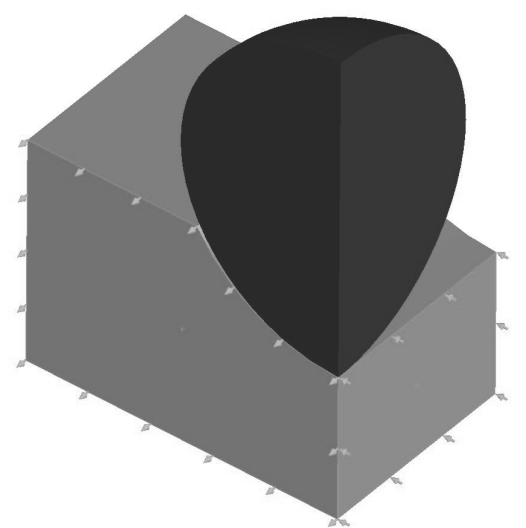

Fig. 8 Symmetrical placement of the part

\section{Loading}

The following loading affects the ball track of the heavy machine:

Permanent loading - the own weight of the ball and the own weight of the rotating top of the heavy machine.

Random loading:

Loading caused by friction when rolling the balls Loading caused by wind at the heavy machine Loading caused by the lean of the heavy machine Loading caused by the own substance of the material on the belt conveyors.

Own weight of the ball track

The loading with its own weight of the model is generated by a programme automatically for the weight acceleration $\mathrm{g}=10 \mathrm{~m} \cdot \mathrm{s}^{-2}$.

Own weight of the rotating top

The weight of the rotating top 1580 tons influences the ball track with the weight force $Q=15800 \mathrm{kN}$. It is divided into $\mathrm{N}=301$ ball with the same distance $\mathrm{s}=125 \mathrm{~mm}$. There is the maximal possible eccentric loading $e=3000 \mathrm{~mm}$ where the value of the maximal weight force $F$, influencing one ball, $F_{\max }=2 Q / N=31600 / 301=105 \mathrm{kN}$. This means a double value with the same distribution of loading $(e=0$ $\mathrm{mm})$. The value of the ball loading is $F_{j m}=52.5 \mathrm{kN}$.

Loading with friction within the rolling ball

The resistance at friction is approximately $1 \%$ of the vertical loading of the ball. This loading is irrelevant. 
Loading with wind at the heavy machine

It is included in the estimation of the own weight of the rotating top.

\section{Loading of the lean of the heavy machine}

It is included in the estimation of the own weight of the rotating top.

Loading of its own weight of the material on the conveyer belts

The probable weight of the material on the conveyor belts is $20 \mathrm{t}$, ie. $1.27 \%$ from the total weight of the rotating top. This loading is irrelevant. Its influence on the eccentricity of the total weight of the rotating top is already included in the estimation of the won weight of the rotating top

The loading of the model - see Fig. 9.

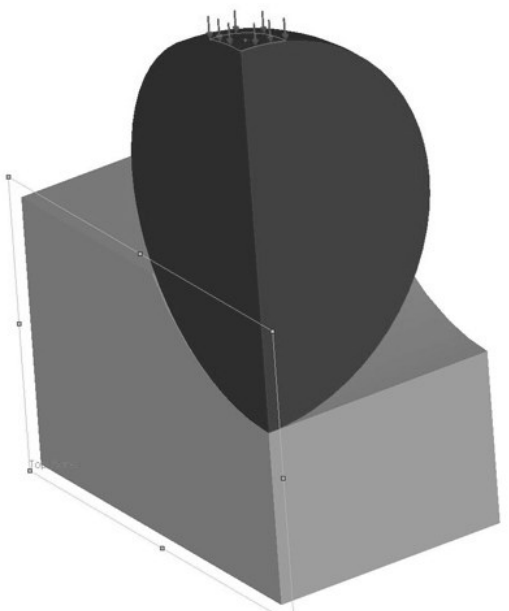

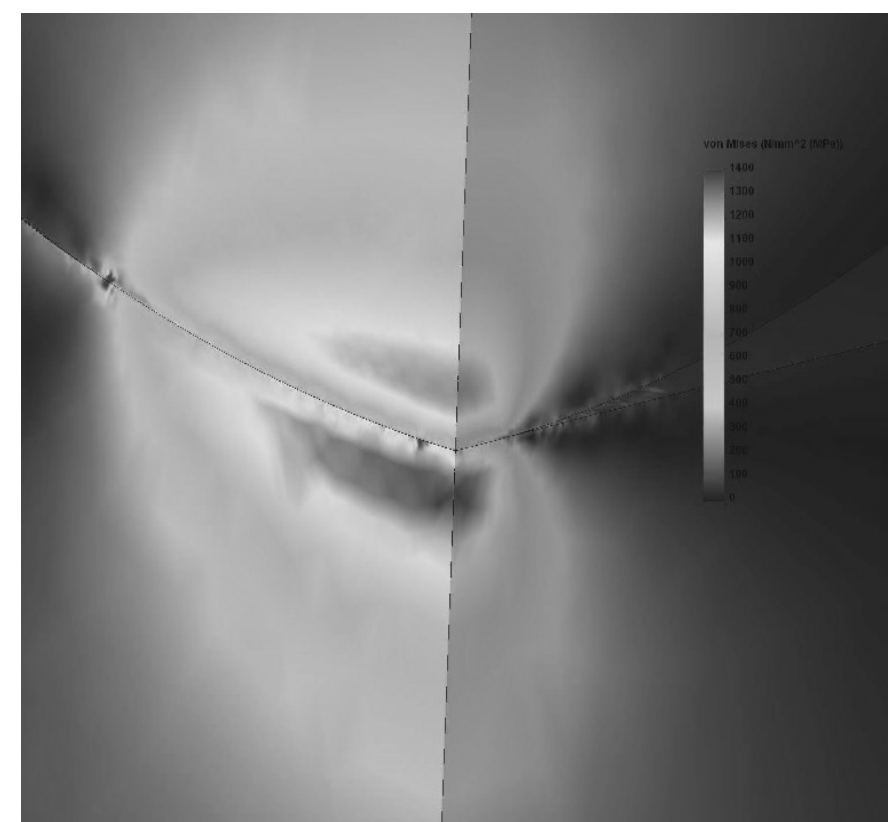

Fig. 10 Effective tenseness for the loading $105 \mathrm{kN}$

\section{EFFECTIVE TENSENESS}

The calculation was made with a linear statics for two loading states. One for the loading of a ball with the force $\mathrm{F}_{\mathrm{jm}}=52.5 \mathrm{kN}$ and for the loading of the ball with the maximal force $F_{\max }=105 \mathrm{kN}$. The contact of the two objects was secured by a condition "no penetration“.

The following (Fig. 10 and 11), show graphical results for the effective tenseness in accordance with the Von Mises Theory in the main planes of the given ellipsoid.

Fig. 9 Loading of the model

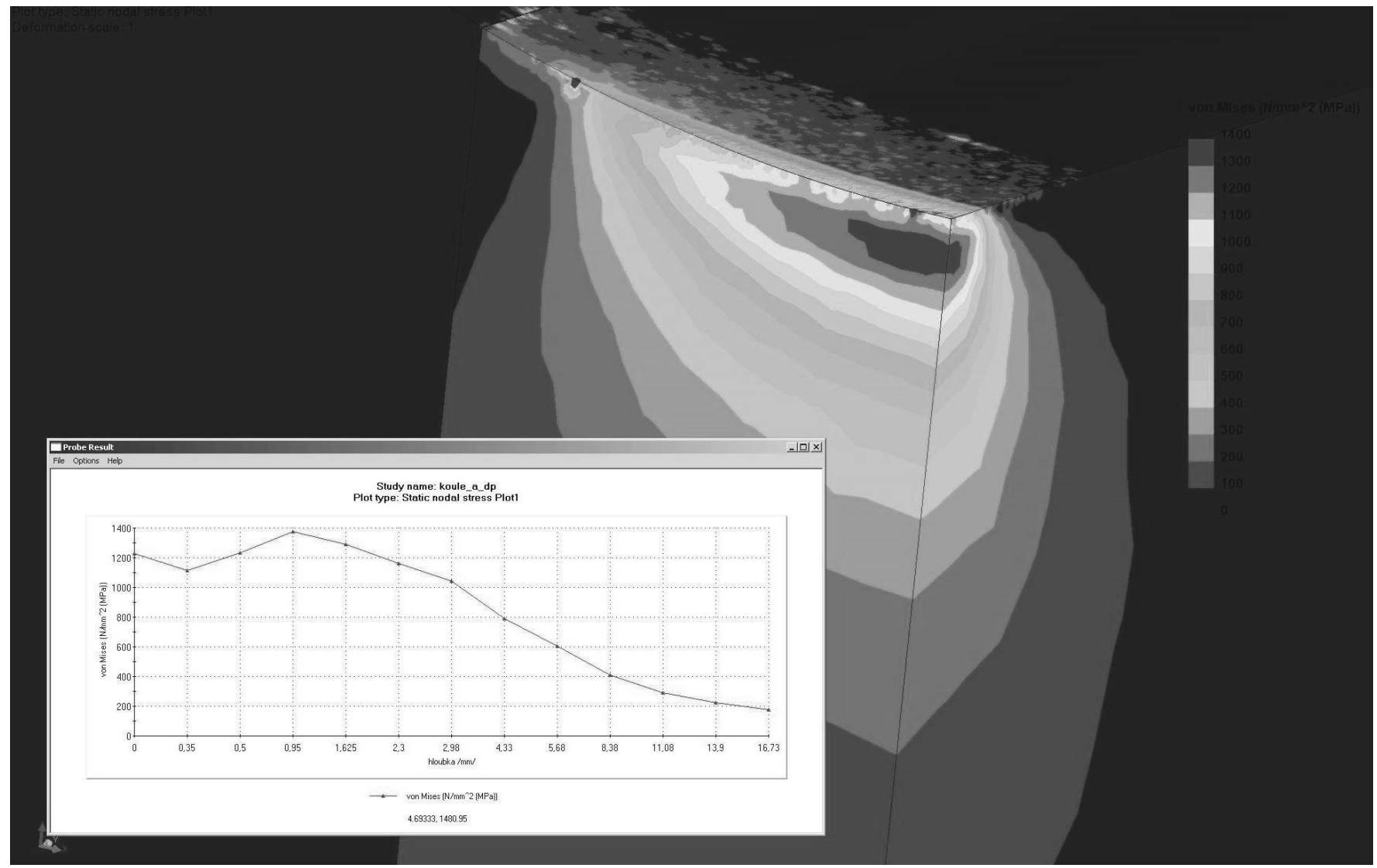




\section{CONTACT PRESSURES}

The following Fig. 12 and 14 are displayed in the graphical form of results for the contact pressures in the main planes of the given ellipsoid. The longer axis of the ellipsoid is located in the plane of the track groove cut, the shorter axis is in the direction of the tangent to the ball track.

Longer axis of the ellipsoid; in connection with the distance from the centre of the contact.

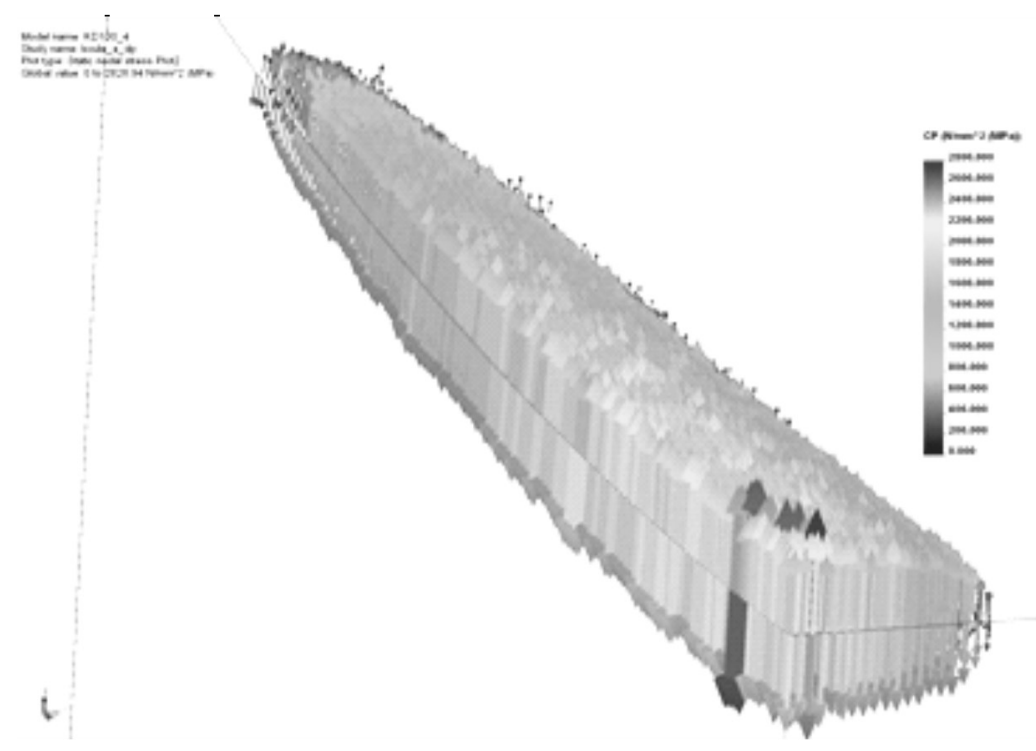

Fig. $12 \frac{1}{4}$ of the ellipsoid for the contact pressures

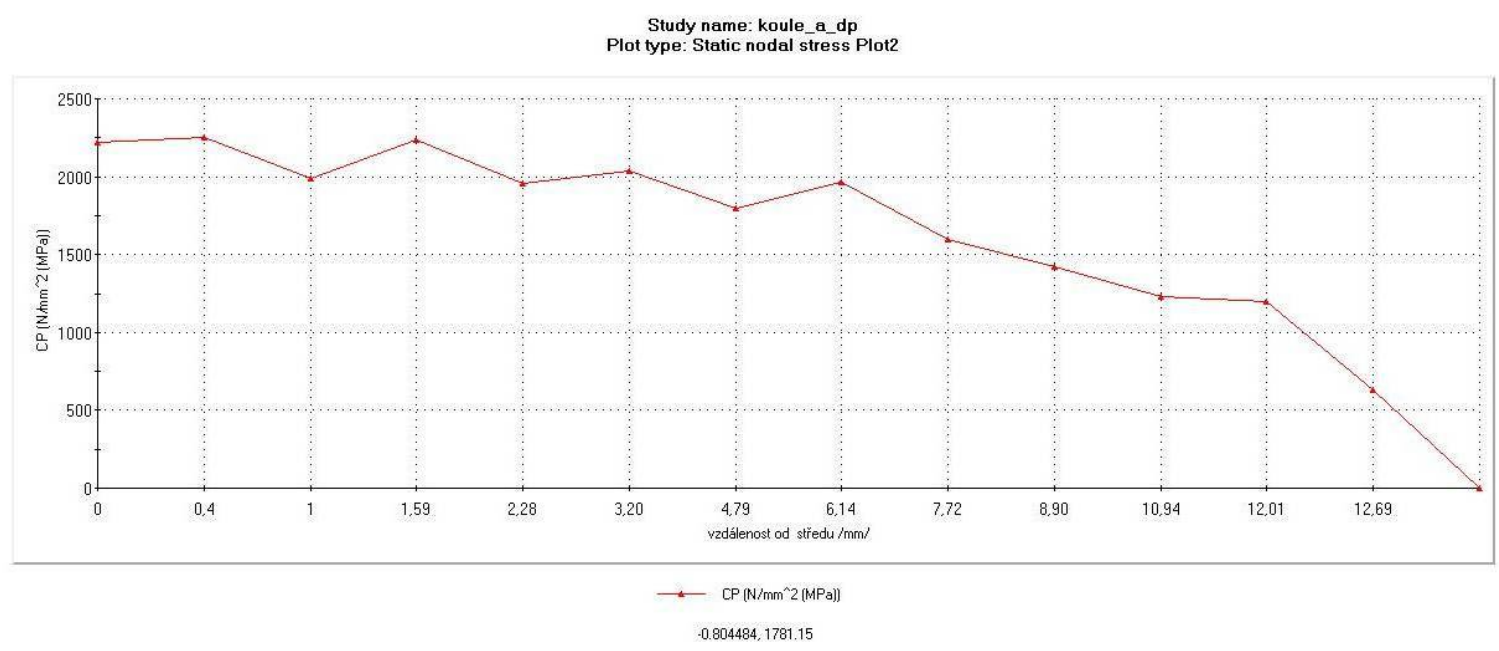

Fig. 13 The contact pressures in the contact of the ball with the bottom part for the loading $105 \mathrm{kN}$

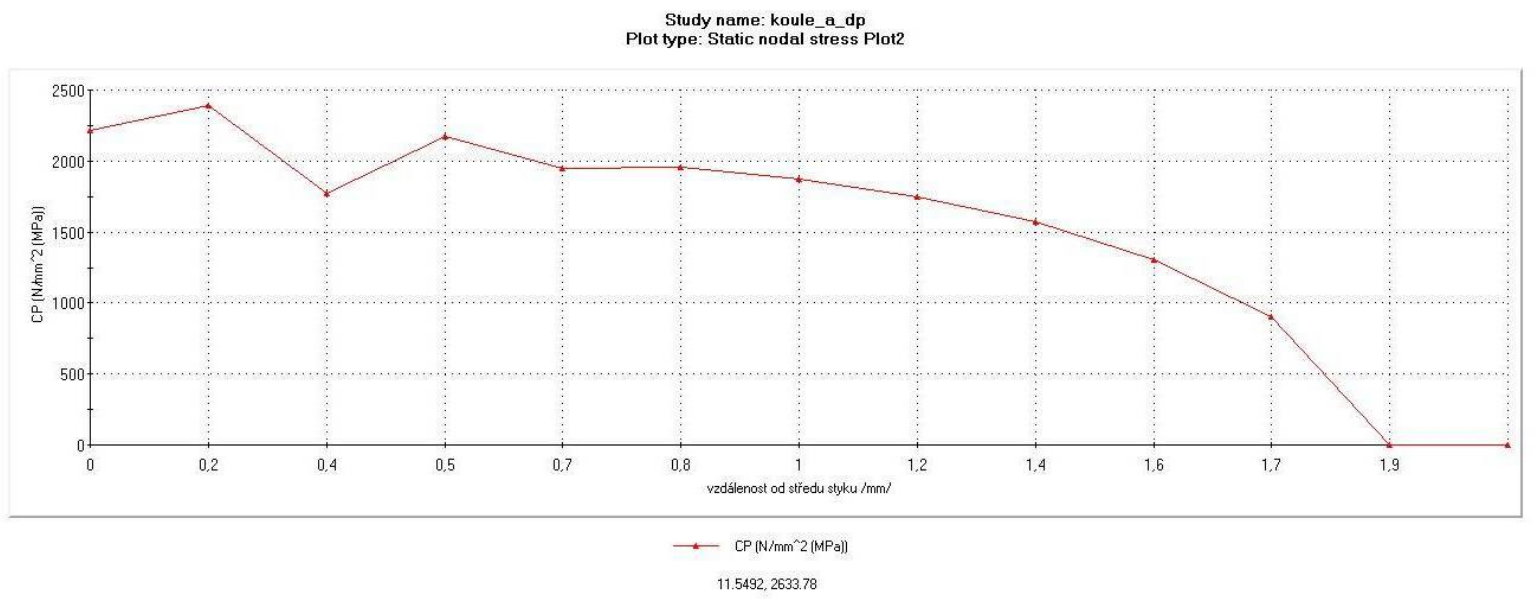

Fig. 14 The contact pressures in the contact of the ball with the bottom part for the loading $105 \mathrm{kN}$, shorter axis of the ellipsoid; in connection with the distance from the centre of the contact 


\section{SUMMARY}

The gained results can be summarized in the following way:

1. Chemical structure proves the declared steel. The content of the carbon overreaches the limit a bit $-0.48 \%$ instead of max. $0.45 \%$.

2. The hardness of the material increases from the surface to the depth 4-6 $\mathrm{mm}$, then it decreases. The values of the hardness are 246-299 HV10. The firmness on the samples from the groove is lower $7 \%$ in comparison with the samples taken out of the groove. The individual samples and their hardness do not overreach $10 \%$.

3. Metallographic analysis showed a change in the structure of samples from the groove crack - the depth was $0.6 \mathrm{~mm}$. The change of the structure mainly depends on the dishomogeneity of the material and on the existence of the holes. The samples out of the groove showed no cracks and less dishomogeneity.

4. The contact pressures were calculated for nominal and maximal loading of the ball. The maximal loading is 105 $\mathrm{kN}$ and represents a double nominal loading and it will be never reached at the machine. The calculated progresses of the contact pressures have a shape of an ellipsoid with the centre in the contact point of both objects, the main axis is horizontal and it is located in the plane of the groove cut, the side axis is horizontal and lies in the plane of the tangent of the ball track. The progresses of the contact pressures in these axis are for the maximal loading and they are shown on the Fig. 13 and 14. The contact pressures reach the maximal value of $2250 \mathrm{MPa}$ in the centre of the objects contact. In accordance with the law of the ellipsoid they decrease to zero. In the main axis the distance is about $12 \mathrm{~mm}$. In the side axis the distance is about $1,9 \mathrm{~mm}$. For the nominal loading of the ball $(52.5 \mathrm{kN})$, the contact pressures reach the maximal value $1600 \mathrm{MPa}$ in the center of the objects contact.

5. Maximal deformation of both objects in the contact point is $0.06 \mathrm{~mm}$. See Fig. 15.

6. Maximal effective tenseness is in the centre of the contact of both objects. It increases from the surface to the depth at about $1 \mathrm{~mm}(1400 \mathrm{MPa})$ and then it decreases. In the depth of $3.6 \mathrm{~mm}$ it is already under the limit of material firmness $880 \mathrm{MPa}$. The progress of the effective tenseness corresponds the laboratory results well in the sense of the plasticization of the material in the places of dishomogeneity into the depth of 0.6-1 $\mathrm{mm}$.

7. The progress of the contact pressures CP (Fig. 16), can be shown by the following graph, where we can specify the equation of the ellipsoid.

8. The above mentioned proves that the material of the bottom part of the ball track is influenced with the operation of the ball track into to depth of about $3.6 \mathrm{~mm}$ (cracks, change of the structure, packing).

9. Before the future use of the parts of the ball track it is recommended to remove the upper layer of the material in the groove to the depth of $3.6 \mathrm{~mm}$.
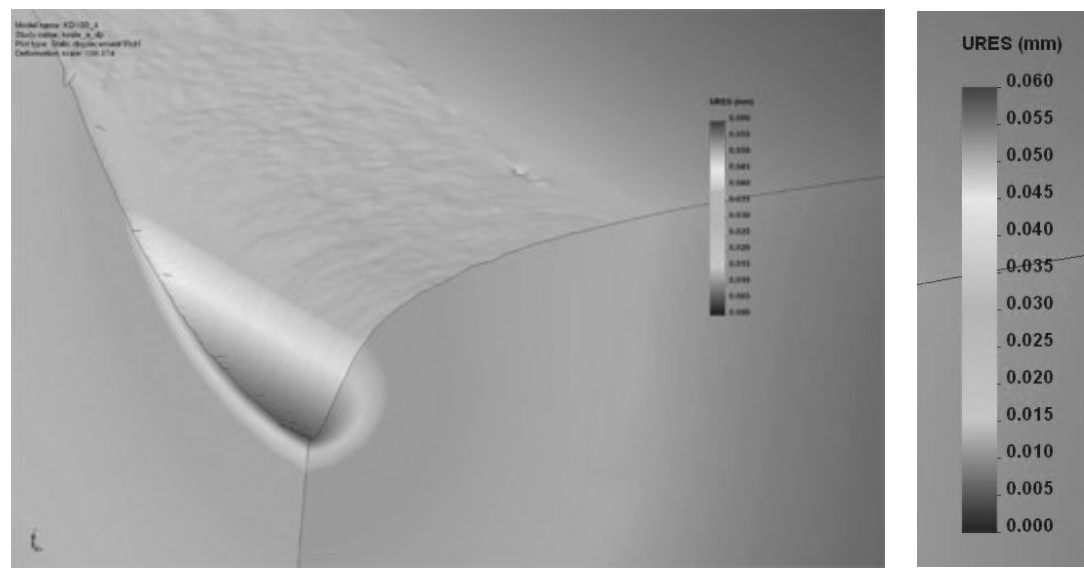

Fig. 15 Deformation of the groove of the track in the contact for loading $105 \mathrm{kN}$

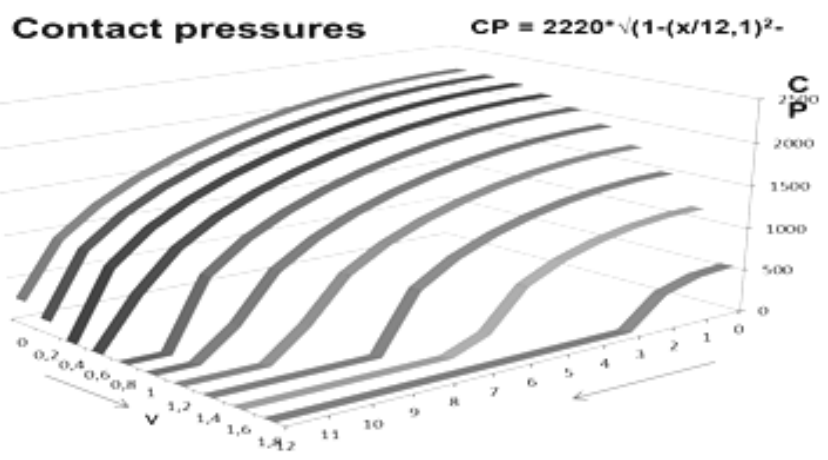

Fig. 16 Contact pressures
The problem was solved and the article was written in cooperation with the companies SD a. s. - Doly Bilina and UNIPETROL RPA s.r.o. The author thanks for cooperation their emplyees who participated in the solution.

\section{REFERENCES}

[1] A. Gabelli and G.E. Morales, Mechanismus poškození vtisky na oběžných drahách valivých ložisek [Online]. Avilable: http://www.skf.com/cz/knowledge-centre/ subscriptions/displayfactbox.html?itemid=54-186690

[2] J. Hojdar, F. Helebrant and H. Gondek, Povrchové dobývací stroje I, Ostrava: VŠB-Technická univerzita Ostrava, 1991.

[3] P. Klouda, Měření stavu kulové dráhy ZP6600/Z79 na $D B$, VÚHU a.s., č.TPD-002/14. 
[4] J. Šimůnek, Části strojů pro povrchovou těžbu kolesová rýpadla, Vítkovice-koncern, Ostrava, 1985.

[5] A.N. Wieczorek, Designing machinery and equipment in accordance with the principle of sustainable development. in Managament Systems in Production Engineering. No. 1(17)/2015 pp. 10-13. DOI 10.12914/ MSPE-05-01-2015

Ing. Petr Klouda, Ing. Vlastimil Moni, Ph.D.

Brown Coal Research Institute j. S.

tř. Budovatelů 2830/3, 43401 Most, CZECH REPUBLIC

e-mail: klouda@vuhu.cz, moni@vuhu.cz

Ing. Jan Blata, Ph.D., Doc. Ing. František Helebrant, CSc.

VSB-Technical University of Ostrava

17.listopadu 15, 70833 Ostrava-Poruba, CZECH REPUBLIC

e-mail: jan.blata@vsb.cz,

frantisek.helebrant@vsb.cz

Ing. Lubomír Donát

Northern energy, a.s.

V. Řezáče 315, 43401 Most, CZECH REPUBLIC
[6] A.N. Wieczorek, W. Polis, Operation-oriented method for testing the abrasive wear of mining chain wheels in the conditions of the combined action of destructive factors. in Managament Systems in Production Engineering. No. 3(19)/2015 pp. 175-178. DOI 10.12914/ MSPE-12-03-2015 